\title{
"El Sexo no es Malo": Maternal Values Accompanying Contraceptive Use Advice to Young Latina Adolescent Daughters
}

\author{
Laura F. Romo - Magali Bravo • Maria Elena Cruz • \\ Rebeca M. Rios • Claudia Kouyoumdjian
}

Published online: 3 February 2010

(C) The Author(s) 2010. This article is published with open access at Springerlink.com

\begin{abstract}
In this study, we utilized observational methods to identify maternal values and concerns accompanying contraceptive use advice in Latina mother-daughter sexuality conversations. The sample included non-sexually active early adolescents around 12 years of age and their mostly Spanish-speaking Latina mothers. Videotaped conversations were coded for the prevalence of messages related to four sexual values (abstinence, delay sex until older, sex is "normal", sex is "improper") and concerns about pregnancy and STD transmission. We examined whether the duration of time spent conversing about these messages was associated with participant characteristics, general communication openness, and the amount of time the dyads spent discussing contraceptive use. Results indicated that Latina mothers who had fewer years of education and lower family income talked longer to their daughters about the need to delay sex, avoid risky situations that would increase their chances of getting pregnant or acquiring an STD, and engage in self-protective practices. Less perceived openness in general communication as reported by both the mothers and the daughters was associated with increased time discussing that sex is improper. Although the duration of contraceptive use messages was brief, mothers and daughters who discussed the fact that sex is normal, and who communicated more about the importance of delaying sex, talked longer about contracep-
\end{abstract}

L. F. Romo $(\bowtie) \cdot$ M. Bravo $\cdot$ M. E. Cruz $\cdot$ R. M. Rios Gevirtz Graduate School of Education, University of California, Santa Barbara, CA 93106-9490, USA

e-mail: 1romo@education.ucsb.edu

C. Kouyoumdjian

California State University,

Los Angeles, CA, USA tive use practices compared to mothers and daughters who engaged in minimal discussion of these sexual values.

Keywords Latina mother-daughter sexuality conversations . Contraceptive use advice Abstinence advice $\cdot$ Female adolescent sexual activity decisions

\section{Introduction}

Mothers play a key role in the sexual socialization of adolescents, which has been shown to positively impact adolescent decision-making about their sexual behavior. As such, an important goal for health interventionists is to design programs that enhance positive aspects of parentadolescent communication about sexuality and target negative interaction patterns. Communication training programs that effectively meet the needs of Latino parents and adolescents are especially needed. According to the National Youth Risk Behavior Survey, 2007, about 50\% of Latino adolescents will have had sexual intercourse at least once by the 12th grade, a significantly higher rate than their European American counterparts (CDC 2007). Also, more than one third of Latino high school adolescents reported that they had not used any form of contraception the last time they had sexual intercourse. Moreover, nearly one in two Latina adolescents will become pregnant at least once before turning age 20, compared to one in five European American adolescents (Martin et al. 2008). The lack of condom use among Latino youth contributes to the high prevalence of STDs in the population (Hamilton et al. 2005), underscoring the need to impress upon adolescents the importance of engaging in self-protective sexual practices. 
Several studies suggest that mother-adolescent sexuality communication can play a critical role in this endeavor. A broader range or a greater number of sexual topics discussed between Latino parents and adolescents have been shown to be linked to fewer adolescent sexual episodes, increased condom use efficacy (Dutra et al. 1999; Hutchinson et al. 2003), and more consistent contraceptive use (East et al. 2005). Similarly, more perceived openness, comfort, and confidence discussing sexuality is associated with less sexual risk-taking and more condom use (Dutra et al. 1999; Halpern-Felsher et al. 2004). Despite the importance of these discussions, there is no or little direct communication between Latino parents and their adolescents about how to protect themselves against negative sexual health outcomes (Ancheta et al. 2005; Dutra et al. 1999; Hutchinson et al. 2003; Miller and Whitaker 2001) particularly with daughters (Raffaelli and Ontai 2001; Raffaelli and Green 2003). Reasons include Latina mothers believing that they lack the knowledge or appropriate language to impart information to their adolescents, or experiencing high level of embarrassment and discomfort (Guilamo-Ramos et al. 2008; O'Sullivan et al. 2001). A better understanding of conversation contexts that help Latina mothers feel comfortable discussing selfprotective practices is needed for designing culturally competent, family-based sexuality communication training programs.

In this study, we analyzed Latina mother-daughter conversations about sexuality to identify maternal concerns and values associated with mothers recommending contraceptive use to young non-sexually active adolescent daughters. As in our previous work with other datasets (e.g., Nadeem and Romo 2008; Nadeem et al. 2006; Romo et al. 2002, 2006) we continue to find this methodology useful for understanding what types of messages Latina mothers deem to be important in communicating with adolescents. The observation coding system was designed to identify the prevalence of three broad message categories and the duration of time that these messages were discussed: sexual values, concerns as measured by warnings about the repercussions of sexual activity, and explicit discussion of contraceptive use practices. Under the category of sexual values, additional coding differentiated four subthemes: (1) sex is a normal, natural act; (2) sex is an improper, morally wrong behavior; (3) the importance of remaining abstinent; and (4) the importance of delaying sex until the girls were older.

A major goal of this study was to examine how time spent on these message types was related to mothers recommending that their daughters use contraceptives in the future. We expected to find that concerns about pregnancy and STD transmission would be prevalent in these discussions (Romo et al. 2002). It is believed that, for the most part, parents rely on scare tactics to help their adolescents avoid engaging in early or unprotected sex (Savin-Williams and Diamond 2004). Indeed, for Latino adolescents, warnings about the repercussions of sexual activity, i.e., pregnancy and STD acquisition, are major themes that surface in discussions with their parents (e.g., Guilamo-Ramos et al. 2007), although the intent may be to alert adolescents to potential dangers, not merely to alarm them. For many adolescents, these messages are warranted, given the high rates of risky sexual behavior in this population (Hamilton et al. 2005). Concerns about protecting their children from negative health outcomes may compel Latina mothers to recommend contraceptive use to daughters despite their discomfort, leading us to hypothesize that increased time spent on warnings would be related to more time spent on contraceptive use messages.

In addition to maternal concerns, sexuality beliefs and values are commonly discussed topics between Latina mothers and adolescents (e.g., Raffaelli et al. 1998; Raffaelli and Green 2003; Romo et al. 2002), and these messages may influence the extent to which mothers discuss self-protective practices. For example, in a survey study that included a large sample of Latinos, Miller and Whitaker (2001) found that maternal endorsement of abstinence was associated with less communication with adolescents about condom use. We hypothesized that a similar trend would surface in our analyses of Latina mother-adolescent conversations. Moreover, we hypothesized that mothers and daughters would spend more time discussing the importance of remaining abstinent in comparison to messages that daughters should delay sex until older, given that Latina daughters are expected to remain virgins until marriage (e.g., Gil and Vasquez; Marin 2003; Villarruel 1998).

We were also interested in the extent to which Latina mothers and daughters discussed positive aspects of sexuality. Little work has been undertaken to understand maternal views on normative sexual development in adolescence, such as whether Latina mothers perceive that their daughters' desires to have sex one day is normal and not morally wrong. Much like other areas of psychosocial development, adolescents face several developmental challenges, such as realizing that sexual desires are normal, feeling comfortable with their choice to abstain from or engage in sexual activity, and understanding how to practice safe sex (Brooks-Gunn and Paikoff 1993; SavinWilliams and Diamond 2004; Steinberg 2005; Tolman et al. 2003). Current research suggests that Latina motherdaughter communication about positive aspects of sexuality is not typical. Latina daughters receive messages that non-marital sexual activity is morally wrong (Gilliam 2007), fostering a loss of self-respect and a loss of 
innocence (Zavella 2003; Villarruel 1998), attitudes that have been described as traditional Latino values associated with preserving virginity (Gil and Vazquez 1996). A question of interest in this study was whether increased time spent discussing positive aspects of sexuality would be related to more time spent on contraceptive use advice for the future.

A second goal of the study was to examine whether participant demographic characteristics (ages, years of education, family income, and religiosity) played a role in how much time was spent on messages regarding contraceptive use practices, sexual values (sex is normal, sex is improper, abstinence, delay sex), and warnings about pregnancy and STD transmission. Mothers with young daughters may feel reluctant to discuss certain topics, or the age of the mother could also be a determinant. Religiosity, or the extent to which the adolescents and mothers attended religious services, was included because research shows that sexually active adolescents are less likely to be religious compared to non-sexually active youth (Manlove et al. 2008; Nonnemaker et al. 2003), leading us to hypothesize that religious mothers would spend more time transmitting values related to abstinence compared to less religious mothers.

In addition to demographic characteristics, we examined how perceptions of openness in general communication mother-daughter impacted the content of mother-daughter sexuality communication. Research shows that adolescents who have positive relationships with their parents are likely to share their parents' values and tend to be concerned about parental disapproval of their decisions regarding their sexual behavior (Garnier and Stein 1998; Jaccard et al. 1998). These findings may help explain why a quality parent-adolescent relationship is associated with Latino adolescents delaying the onset of sexual behavior (VélezPastrana et al. 2005). Based on these findings, we hypothesized that values of abstinence and delaying sex would be prevalent in discussions between mothers and daughters who report having openness in their relationship. It was also possible that greater openness would be associated with increased discussion of contraceptive use. The extent to which positive (sex is normal) and negative (sex is improper) themes were related to general communication quality was an open question.

\section{Participants}

Latina mothers and daughters were recruited through flyers and information tables at a local youth-based organization and school parent meetings in 2007. The dyads were invited to attend a mother-daughter communication program about sensitive topics surrounding sexuality and HIV transmission. For program evaluation purposes, the mothers and daughters took part in an initial testing session in which they were videotaped while conversing about dating and sexuality. Data collected from these pretest sessions were analyzed in this study.

Fifty-nine Latina (mostly Mexican immigrant) mothers and their daughters participated. The girls' mean age was 11.7 years $(\mathrm{SD}=.9$; range $=10-13)$. About $23 \%$ were in the 5 th grade, $43 \%$ in 6 th, $22 \%$ in 7 th, and the remainder in 8 th grade. Thirty-six percent of the girls reported that they were the oldest among their siblings, and about another third reported that they were second born. Most of the adolescents $(78 \%)$ were born in the USA. About half $(53 \%)$ reported that they prefer to speak both English and Spanish, and $43 \%$ indicated a preference toward English. All but one reported that Spanish was a dominant language spoken at home. About $78 \%$ reported that they were Catholic, and $76 \%$ indicated that they attended religious services often or regularly. None of the girls reported that they had ever engaged in sexual intercourse.

The mothers' mean age was 36.2 years $(\mathrm{SD}=5.4$; range $=$ 26-50). Most mothers (83\%) were foreign-born, with the majority (80\%) reporting that Mexico was their country of origin. The rest were born in other parts of Latin America or did not specify. About $45 \%$ reported that they usually spoke in both English and Spanish, and another 45\% indicated that they spoke most of the time or always in Spanish. The mothers had completed a mean of 9.8 years of education $(\mathrm{SD}=3.9)$. Only $28 \%$ had completed high school or beyond. About half of the mothers were single or never married, $21 \%$ were married or living together with a partner, and the remainder were divorced, separated, or widowed. The median household income was $\$ 15,000$ 20,000 per year, ranging from under $\$ 10,000$ to over $\$ 60,000$ a year. About $90 \%$ of the mothers reported that they were Catholic, $92 \%$ indicated that they attended religious services, and $80 \%$ attended often. None of the mothers reported that they believed that their daughters were engaging in sexual activity.

\section{Procedure}

Research sessions lasted approximately $1-2 \mathrm{~h}$ and were conducted in the dyad's preferred language (English, Spanish, or a combination) in a private room at a local youth-based organization. A few dyads were tested at a university laboratory. All dyads had been told in advance that as part of the research session they would be videotaped. The participants were compensated $\$ 20$ for their time.

After reviewing and signing consent forms, the dyad was asked to discuss three topics for $7 \mathrm{~min}$ each: dating and 
sexuality, conflict, and HIV transmission. The order of the conversations was counterbalanced across dyads. The experimenter introduced each topic by stating, for example, "For the next 7 minutes, I would like for you to talk about dating and sexuality." The dyad was asked if they had any questions, which the experimenter addressed before leaving the room. Importantly, no specific instructions were given about what themes they should include in their discussions. The same procedure was repeated for the second and third topics. After the conversations, the mothers and adolescents were separated to fill out questionnaires in their preferred language. This study was approved by the Institutional Review Board at the University of California, Santa Barbara.

\section{Questionnaire Measures}

Demographic Questionnaire The adolescents completed a questionnaire requesting information about their age, birth place, birth order, years of education, preferred language spoken, and languages spoken by adults at home. The girls were also asked if they had ever engaged in sexual intercourse. The mothers were asked similar questions regarding age, birth place, years of education, and preferred language spoken. Additional questions were asked about their marital status, income (measured on a seven-point scale ranging from $\$ 5,000$ to over $\$ 60,000$ per year), and religious background. The mothers were asked to report whether they believed that their daughters were sexually active.

\section{Adolescent and Maternal Self-reported Open Communication} The adolescents' and mothers' perceptions of open communication were measured using the open communication subscale from the Parent-Adolescent Communication (PAC) scale (Barnes and Olson 1986). The 10-item subscale assesses the extent to which the adolescents and their mothers feel that they can openly communicate with each other. Participants answered each question on a five-point Likert scale ranging from 1, "strongly disagree" to 5, "strongly agree." Examples of items making up the open communication subscale include, "I find it easy to discuss problems with my mother/daughter," "My mother/daughter understands my point of view," and, "When I ask questions, I get honest answers from my mother/daughter." The PAC has been validated cross-culturally for use with Latino adolescents (Knight et al. 1992). In the current study, Cronbach alphas for the open communication scale were .90 for the adolescents and .88 for the mothers.

Observation Measures Only the dating and sexuality conversations were analyzed for the current study. A computer program designed to code interaction (Noldus
Information Technology 2007) was used to code information about the sexuality messages throughout the entire $7 \mathrm{~min}$ of the videotaped conversation. The coding system identified, classified, and recorded the duration of each message discussed in the conversations. Two bilingual graduate students were trained to code the videotapes. The coders were initially trained together on $1 \%$ of the tapes and an additional $10 \%$ of the tapes were separately coded for reliability purposes. An intraclass correlation to assess inter-rater reliability was separately calculated for each message subtheme. Intraclass correlation coefficients were .72 for sex is normal, .98 for sex is improper, .86 for abstinence, .85 for delay sex, .87 for warnings about pregnancy, .97 for warnings about STDs, and .92 for explicit contraceptive use. Two representative examples of the content of each message type are included in Spanish (English translations), with ID numbers and the rounded ages of the mothers and daughters [M:years; D:years].

\section{Contraceptive Use Practices}

- ID145 [M:48; D:12 years]: M: "Cuando tienen relaciones... tienen que usar siempre, tienen que protegerse con..., yo creo que tú conoces los condones." (M: "When you have sexual relations... you have to always use, you have to protect yourself with..., I think you know what condoms are.").

- ID 125 [M:30; D:12 years]. M: "Tú sabes que hay muchas enfermedades y para eso también hay protección. Hay protección, para eso están los preservativos, los condones, para eso es, para la protección." (M: "You know that there are a lot of diseases and there is also protection for that. There is protection, that is why there are contraceptives, condoms, they are for that, for protection.").

Warnings about Pregnancy and STD Transmission

- ID 101 [M:31; D:11 years]: M: "Hay niñas que todavía ni terminan la escuela, andan ya con sus bebés cargando. Tu has visto en la calle las niñas embarazadas y van a la escuela. ¿A ti no te gustaría nada así, verdad que no? ¿Umm? Por que te imaginas, para mantener un hijo, todo el sacrificio que es." (M: "There are girls who are not even done with school yet and are already carrying their babies. You have seen those pregnant girls in the street and they go to the school. You wouldn't like anything like that, right? Huh? Can you can imagine, supporting a child, all the sacrifice that is involved").

- ID 134 [M:33; D:12 years]: M: "El día que tu decidas tener un novio y decidas tener sexo con él tienes que 
cuidarte por que no sabes si él ya estado con otras muchachas que tienen otras enfermedades y hay muchas, muchas, muchas enfermedades tantas que no te imaginas" (M: "The day that you decide to have a boyfriend and decide to have sex with him, you have to take care of yourself because you don't know if he has been with other girls that have diseases, and there are many, many, many diseases, you can't even imagine how many there are").

\section{Sexual Values Subthemes}

\section{Sex is Normal}

- ID 104 [M:38; D:12 years]: M: "Para mi parecer yo no soy de esas mamas cerradas que digan, 'hay no, yo quiero que mi hija sea una santa'. Sí pienso que es normal en este país que estamos, es normal que los niños y las niñas tengan sexo." (M: "In my mind, I am not one of those closed-minded mothers who say 'oh no, I want my daughter to be a saint.' I do think that in this country that we are in, it is normal for boys and girls to have sex.").

- ID 113 [M:31; D:12 years]: M: "Pero el sexo, el sexo no es malo. Esa es tu pregunta, que si es malo? No es malo." (M: "But sex, sex is not bad. Is that your question, if it is bad? It is not bad.").

2. Sex is Improper

- ID 102 (M:42; D:13 years): M: "Porque a cualquier muchacho, le dices que si quieres ser su novia, y ya te quiere andar metiendo la mano debajo de la blusa, y ya te quiere andar metiendo las manos en la cola, y ya te quiere andar... Y tu crees que eso esta bien?" D: "Mm-mm (no)." M: "Y si a la niña le gusta, pos lo deja, que siga agarrando. ¿Y ya de ahí, que pasa? De ahí, vienen las relaciones sexuales." (M: "Because, if to any guy, you tell them you want to be their girlfriend, then they want to start putting their hand under your blouse, and then they want to start putting their hands on your bottom and then they want to .... Do you think that is okay?" D: "Mm-mm [no]." M: "And if the girl likes it, well she'll let him, and he will keep groping her. And from there, what happens? From there, sex occurs.").

- ID 137: [M:33; D:12 years]: M: "Porque uno de mujer vale una ves. Una mujer pierde muchas cosas. Pierde la dignidad, pierde la virginidad. Pierde que la gente hable de uno." (M: "Because as women, we are worth something only once. A woman can lose many things. She loses her dignity, her virginity. She loses out because people talk.").
3. Abstinence

- ID 147 [M:44; T:12 years]: M: "Yo cuando me casé, yo me quise casar de blanco y me casé de blanco_" D: [interrupts] "Pero la segunda vez ya no ¿verdad? M: Pues ya no se podía porque supuestamente la primera vez que uno se casa, es la primera vez que uno va a tener sexo. Nunca jamás lo has tenido y por eso se casan de blanco." (M: "When I got married, I wanted to marry in a white dress, and I got married in white_-" D: [interrupts] "But the second time you didn't, right?" M: "Well it was no longer possible because supposedly the first time you get married, it is also the first time you are going to have sex. You have never done it before and that is why you get married in white.").

- ID 140: [M:38; D:11 years]: $M$ : “ ¿Y cuando el noviazgo ya es de muchos años, que tienen dos, tres años de novios? D: Sí, si todavía están bien, con los dos se pueden casar. And then, umm...agarran su casa $y$ viven junto, and then, empiezan a tener relaciones." M: "Si." (M: "What about when a relationship has been going on for many years, going on two, three years of dating?" D: "Yes, if they are still good for each other, they can get married, and then, umm...they get their house and live together, and then they start to have sexual relations." M: "Yes.").

4. Delay Sex Until Older

- ID 104 [M:38; D:12 years]: M: "Entiendeme. Hay tiempo para todo. Poco a poco uno va creciendo, va tieniendo noviecitos, después tiene sexo después." (M: "Understand me. There is time for everything. Little by little one grows up, has little boyfriends, and later on has sex, later.").

- ID 113 [M:31; D:12 years]: M: “ ¿Porque hasta los 18 años dices tú que puedes tener relaciones?" D: - [shrugs her shoulders] M: "Tal vez porque pienses que es más seguro para ti ¿No? Osea, vas a tener mas conocimiento de los que estas haciendo $y$ vas a saber lo que estas haciendo, más que si tuvieras sexo de 13, de 12, o de 14 años. ... Pero, si estas ya mas de una edad vas a saber lo que estas haciendo, ¿no?”. (M: "Why do you say that you can have sex at age 18?" D: - [shrugs her shoulders]. M: "Maybe because you think that it may be safer for you, right? Well, you are going to have a better understanding of what you are doing, and you are going to know what you are doing more so than if you had had sex at 13,12 , or 14 years of age. ...But, at an older age you are going to know what you are doing, right?"). 


\section{Results}

The Proportions of Mother-Daughter Dyads Discussing the Various Message Types

As a first step in these analyses, we examined the proportions of mother-daughter dyads who discussed the various message types (i.e., sexual values, warnings about negative repercussions, and explicit discussion of contraceptive use practices). The results are presented in Table 1. About two thirds of the dyads discussed sexual values and almost half of the dyads discussed warning messages. The proportion of dyads who discussed contraceptive use practices was less than one fourth of all participants. Within the category of sexual values, about half of all dyads discussed the importance of delaying sex until daughters were older. Roughly $30 \%$ of the dyads communicated positive views about sexuality that sexual behavior was normal. About one fifth of the dyads mentioned that sex was improper. The proportion of dyads who talked about the importance of postponing sex until marriage was less than $20 \%$.

The Duration of Time Spent on the Various Message Types

The right half of Table 1 presents the means and standard deviations associated with the amount of time that the dyads spent discussing sexual values, warnings, contraceptive use, and each of the six subthemes. The means include zeroes for dyads who did not discuss the topic. To evaluate the differences among the category means, we conducted a one-way repeated measures ANOVA with sexual values, warnings, and contraceptive use as the within-subjects variables. The test was statistically significant $[F(2,116)=$ $7.56, p<.001]$. Tukey post hoc tests conducted to evaluate pairwise differences between means revealed that the dyads spent more time talking about sexual values and warnings in comparison to contraceptive use $(p \mathbf{s}<.05)$, but the duration of time spent talking about sexual values and warnings did not differ.

A second one-way repeated measures ANOVA was performed to evaluate differences among the means of the six subthemes (sex is normal, sex is improper, abstinence, delay sex, pregnancy warnings, and STD transmission warnings $)$. This test was also statistically significant $[F$ $(5,290)=6.01, p<.001]$. Tukey post hoc tests revealed that the dyads spent more time talking about the importance of delaying sex compared to messages that sex is normal, sex is improper, and values of abstinence $(p s<.05)$. The remaining sexual values subthemes did not differ from one another.

Participant Characteristics and the Duration of Time Spent on the Various Message Types

Correlational analyses were conducted in order to explore the relationships among participant characteristics (adolescent and maternal ages, religiosity, education level, family income, and reports of openness in the mother-daughter relationship) and the duration of time spent on the message types. Mothers with fewer years of education spent more time warning about pregnancy and STD transmission $[r(58)=$ $-.37, p<.01]$, and more time on messages that their daughters should delay sex until they were older $[r(58)=$ $-.28, p<.05]$. Mothers from lower income backgrounds engaged in longer discussions about contraceptive use than did mothers from higher income levels $[r(57)=-.28, p<.05]$. Increased time spent on messages about the impropriety of adolescent sexual behavior was associated with the adolescents $[r(56)=-.27, p<.05]$ and the mothers $[r(54)=-.47$, $p<.001]$, reporting less of openness in their general communication. Adolescent perceptions of communication openness were positively correlated with time spent on messages that they should delay sex until they were older $[r(56)=.28$, $p<.05]$. The remaining correlations were not significant.

Table 1 Proportion of mother-daughter dyads discussing various messages types and mean duration (SD) of messages in seconds $(N=59)$

\begin{tabular}{llcr}
\hline Types of conversation messages & Proportion of dyads & Mean duration in seconds (SD) $^{\mathrm{a}}$ \\
\hline Total sexual values & $68 \%$ & $29 \%$ & $30.2(35.0) \mathrm{a}$ \\
$\quad$ Sex is normal & & $22 \%$ & $5.1(10.4) \mathrm{a}$ \\
Sex is improper & & $17 \%$ & $4.7(12.0) \mathrm{a}$ \\
Abstain from sex & & $49 \%$ & $3.0(8.9) \mathrm{a}$ \\
Delay sex until older & $46 \%$ & & $17.6(29.2) \mathrm{b}$ \\
Warnings about pregnancy and STDs & $20 \%$ & $9.3(27.4) \mathrm{b}$ \\
Contraceptive use practices & & & \\
\hline
\end{tabular}

Different letters within columns indicate that the means are significantly different from one another $(p s<.05)$.

${ }^{a}$ Means include zeroes for dyads who did not discuss the topic. 
Predictors of Discussion of Contraceptive Practices

To evaluate how the duration of time spent on maternal concerns and values was associated with time spent on contraceptive use advice, we conducted a hierarchical multiple regression analysis in which contraceptive use messages constituted the dependent variable. We controlled for income level given its significant negative correlation with contraceptive use advice. This variable was entered in step 1 of the analysis. Warnings about pregnancy and STD transmission and each of the four sexual value messages were entered in the second step. As shown in Table 2, family income was significantly related to contraceptive use advice $[F(1,57)=4.92, p<.05]$. Adding the message types at step 2 explained additional variance $[F(5,52)=3.19, p<.05]$. We found that time spent on positive views of sexuality was associated with contraceptive use advice. That is, mothers and daughters who engaged in more discussion that sexual behavior is normal spent longer periods of time discussing contraceptive use practices. Messages about abstinence, sex is improper, that daughters should delay sex until older, and warnings about pregnancy and STD transmission were not significantly related to discussion about contraceptive use.

\section{Discussion}

Numerous survey studies suggest that contraceptive use tends to be among the least discussed topics between Latina parents and adolescents, particularly daughters (e.g., Ancheta et al. 2005; Hutchinson et al. 2003; Raffaelli and Green 2003). To date, we know little about maternal concerns or values, or mother-daughter characteristics, that may inhibit or promote these discussions. In this study, we analyzed videotaped Latina mother-daughter conversations about sexuality to examine how pregnancy and STD

Table 2 Regression analysis with maternal concerns and values predicting time spent on contraceptive use messages

\begin{tabular}{lll}
\hline Predictors & $\begin{array}{l}\text { Step 1 } \\
\beta 1\end{array}$ & $\begin{array}{l}\text { Step 2 } \\
\beta 2\end{array}$ \\
\hline Family income & $-.28^{*}$ & -.22 \\
Warnings about pregnancy and STD transmission & & -.07 \\
Sex is normal & .27 \\
Sex is improper & -.09 \\
Delay sex until older & .26 \\
Abstinence & -.09 \\
$\Delta R^{2}$ & $.08 *$ & $.22 *$ \\
\hline
\end{tabular}

Final model, $F(6,52)=3.64, p<.01 ; R^{2}=.30$

$* p<.05$ transmission warnings and messages about sexual values were associated with the mothers recommending contraceptive use to their young non-sexually active adolescent daughters.

As expected, our analyses revealed that Latina mothers place high priority on transmitting their values when communicating with their adolescents about sexuality, with over two thirds of the dyads discussing their beliefs. When broken down by subthemes, we were somewhat surprised that time spent on abstinence was extremely brief in comparison to messages that daughters should delay sex until older. Moreover, neither the mothers' nor their daughters' reports of religiosity determined the amount of time that they spent talking about abstinence, despite the fact that it is considered a Catholic/Christian value and the vast majority of the participants reported that they were Catholic and attended church often. Although abstinence is highly valued in the culture, we found that many lowincome Latina mothers, regardless of religiosity, accept that their daughters will engage in sexual activity one day and that it may not necessarily occur within the context of a marriage relationship.

With respect to positive and negative portrayals of sexual activity, time spent on both themes was very short. Hence, maternal views about sexual intercourse were not generally positive but neither were they overwhelmingly negative. This finding is important given research suggesting that a large majority of Latina adolescents are exposed to messages that sexual behavior is shameful and immoral. However, this conclusion has been drawn from qualitative research findings obtained from small sample sizes (e.g., Gilliam et al. 2004; O'Sullivan et al. 2001; Zavella 2003), which may have led us to overestimate the extent to which sex-is-improper messages are dominant in these discussions. On the other hand, in a recent quantitative study with a large sample, Latino adolescents reported that they were exposed to negative messages quite frequently (Guilamo-Ramos et al. 2007), raising further questions about the prevalence of these message types. Another possible explanation for the low incidence of negative messages in our study is that our sample was very different from the previously mentioned studies. About half of the mothers in our study were single, which may have influenced the types of sexuality message they deemed to be important to communicate with daughters.

A variable related to the prevalence of certain message types was the quality of mother-daughter communication in general. Adolescents who reported more openness in general communication spent more time talking to their mothers about the importance of delaying sex until older, which is consistent with the literature that a good quality parent-adolescent relationship is associated with Latino 
adolescents delaying sexual debut (e.g., Vélez-Pastrana et al. 2005). One of our most interesting findings is that increased time spent on sex-is-improper messages was associated with the mothers and daughters reporting less openness in their general communication. Perhaps when lines of communication are closed, Latina mothers rely on negative sexuality messages as a strategy for deterring their daughters from engaging in sexual activity. Intervention programs are needed to help Latina mothers develop positive ways for communicating to daughters about their sexual values, especially for mothers and daughters who experience problems communicating in general.

Socioeconomic status influenced time spent on warnings about the repercussions of sexual activity. Specifically, Latina mothers who had fewer years of education talked longer to their daughters about the need to avoid risky situations that place them at risk for pregnancy and STD transmission. In addition, mothers from low-income backgrounds talked longer about contraceptive use practices compared to mothers from higher income backgrounds. These findings are consistent with results from a national sample of middle school students showing that adolescents who live in disadvantaged neighborhoods have parents who communicate more about negative consequences of sexual activity compared to adolescents living in higher income neighborhoods (Roche et al. 2005). We speculate that the link between socioeconomic variables and warnings about negative consequences and contraceptive use advice is mediated by maternal worries about the high rates of teenage pregnancies in their neighborhoods. These concerns then trigger warnings to daughters about the consequences of sexual activity. Given their apprehension, less-educated, low-income immigrant parents may view contraceptive use advice as a necessary part of responsible parenting, which may supersede their concerns about violating personal values related to culture or religion.

As expected, a small proportion of mother-daughter dyads discussed the topic of contraceptive use practices and the duration of these messages were short. Because none of the mothers believed that their daughters were engaging in sexual activity, many mothers may have perceived the topic to be irrelevant. Or, as other research has proposed, the mothers could have felt uncomfortable (Meneses et al. 2006) or believed that they lacked the communication skills to discuss the topic (O'Sullivan et al. 2001). For the purposes of this study, we were interested in whether sexual values and warnings were associated with contraceptive use advice. Our analyses revealed that mothers and daughters who talked longer about the normality of sexual feelings engaged in more discussion about contraceptive use practices compared to mothers and daughters who engaged in minimal or no discussion of these sexual values. Because our focus as researchers has leaned towards understanding challenges to effective sexuality communication, the question of whether mothers communicate positively about sexuality to daughters and the implications of these messages has been understudied.

\section{Limitations}

One limitation of observational research is that it may invoke social desirability because of its lack of anonymity. For example, some mothers may have avoided lecturing their daughters about the impropriety of sexual behavior so as not to present themselves negatively on video. A second limitation is that the majority of our participants took part in this study because they were invited to later attend a workshop with their daughters to receive information on sexuality and reproductive health. Latina mothers who are willing to attend such workshops may communicate differently with their daughters compared to those who do not. A third limitation is that this study was conducted with a very low-income sample of mostly Latina immigrant mothers of Mexican heritage, limiting the generalizability of these findings to US-born Latina women and daughters from higher income backgrounds.

\section{Implications for Sexuality Education Programs}

During the last 15 years, several investigators in the field of pregnancy prevention have conducted evaluations on the effectiveness of programs espousing abstinence-only and comprehensive programs that include abstinence as a component. The general consensus among health researchers is that programs that teach both about abstinence and contraceptive use are more effective at preventing pregnancy, STDs, and risky sexual behavior than abstinence alone (Kirby 2007; Santelli et al. 2006). The major reason is that youth in abstinence-only programs are no more likely to abstain from sex than youth who do not attend these programs (Rosenbaum 2009). Unfortunately, they are unlikely to use any measures to protect themselves from pregnancy and disease when they initiate sexual activity (Bearman and Bruckner 2001).

An important question is whether parents who endorse abstinence are open to family-based comprehensive sexuality education programs that include both messages of abstinence and contraceptive use. Many parents report that they want to be able to give advice to their adolescents about the best course of action to take should they decide to become sexually active (National Campaign to Prevent Teen Pregnancy 2001). The findings from our study suggest that, despite their religiosity, many low-income Latina immigrant mothers have accepted the reality that their daughters will be sexually active at some point, and want to encourage them to delay sex for as long as possible. In 
general, we speculate that discussions about abstinence did not dominate the mother-daughter conversations that we observed, because low-income Latina mothers may be compelled by their concerns to give their daughters the best advice possible about how to protect themselves from potential negative health consequences. In addition, general acceptance of their daughters' sexuality may be the first step in helping mother overcome the challenges of talking about contraceptive use before their daughters are sexually active.

Acknowledgments Funding for this article was provided in part by a William T. Grant Scholar's award to the first author. We thank Jeanne Tschann for her comments on an earlier draft of this paper.

Open Access This article is distributed under the terms of the Creative Commons Attribution Noncommercial License which permits any noncommercial use, distribution, and reproduction in any medium, provided the original author(s) and source are credited.

\section{References}

Ancheta, R., Hynes, C., \& Shrier, L. A. (2005). Reproductive health education and sexual risk taking among high risk female adolescents and young adults. Journal of Pediatric and Adolescent Gynecology, 18(2), 105-111.

Barnes, H., \& Olson, D. H. (1986). Parent-adolescent communication. In D. H. Olson, H. I. McCubbin, H. Barnes, A. Larson, M. Muxen, \& M. Wilson (Eds.), Family inventories (pp. 33-48). St. Paul: University of Minnesota, Family Social Science.

Bearman, P., \& Bruckner, H. (2001). Promising the future: virginity pledges and the transition to first intercourse. American Journal of Sociology, 106, 859-912.

Brooks-Gunn, J., \& Paikoff, R. L. (1993). "Sex is a gamble, kissing is a game": adolescent sexuality and health promotion. In S. G. Millstein, A. C. Petersen, \& E. O. Nightingale (Eds.), Promoting the health of adolescents: new directions for the twenty-first century (pp. 180-208). New York: Oxford University Press.

Centers for Disease Control and Prevention National Youth Risk Behavior Survey (2007). http://www.cdc.gov/healthyyouth/yrbs/pdf/ yrbs07_us_disparity_race.pdf.

Dutra, R., Miller, K. S., \& Forehand, R. (1999). The process and content of sexual communication with adolescents in two-parent families: associations with sexual risk-taking behavior. AIDS and Behavior, 3(1), 59-66.

East, P., Reyes, B., Contreras, B., Wu, R. C., \& Contreras, R. (2005). Positive adolescent sexuality as evident in consistent and reliable contraceptive use: a study of sexually active Latino and nonLatino youths' contraceptive behavior. Sexuality Research and Social Policy: Journal of NSRC, 2(4), 42-53.

Garnier, H. E., \& Stein, J. A. (1998). Values and the family: risk and protective factors for adolescent problem behaviors. Youth \& Society, 30, 89-120.

Gil, R. M., \& Vazquez, C. I. (1996). The Maria paradox: how Latinas can merge old world traditions with new world self-esteem. New York: Perigee.

Gilliam, M. L. (2007). The role of parents and partners in the pregnancy behaviors of young Latinas. Hispanic Journal of Behavioral Sciences, 29(1), 50-67.

Gilliam, M., Warden, M., \& Tapia, B. (2004). Young Latinas recall contraceptive use before and after pregnancy: a focus group study. Journal of Pediatric Adolescent Gynecology, 17, 279287.

Guilamo-Ramos, V., Jaccard, J., Dittus, P., Bouris, A., Holloway, I., \& Casillas, E. (2007). Adolescent expectancies, parent-adolescent communication and intentions to have sexual intercourse among inner-city, middle school youth. Annals of Behavioral Medicine, 34(1), 56-66.

Guilamo-Ramos, V., Jaccard, J., Dittus, P., \& Collins, S. (2008). Parent-adolescent communication about sexual intercourse: an analysis of maternal reluctance to communicate. Health Psychology, 27(6), 760-769.

Halpern-Felsher, B. L., Kropp, R. Y., Boyer, C. B., Tschann, J. M., \& Ellen, J. M. (2004). Adolescents' self-efficacy to communicate about sex: its role in condom attitudes, commitment, and use. Adolescence, 39(155), 443-456.

Hamilton, B. E., Martin, J. A., Ventura, S. J., Sutton, P. D., \& Menacker, F. (2005). Births: preliminary data for 2004. National Vital Statistics Reports, 54(8), 1-17.

Hutchinson, M. K., Jemmott, J. B. I., Jemmott, L. S., Braverman, P., \& Fong, G. T. (2003). The role of mother-daughter sexual risk communication in reducing sexual risk behaviors among urban adolescent females: a prospective study. Journal of Adolescent Health, 33(2), 98-107.

Jaccard, J., Dittus, P. J., \& Gordon, V. V. (1998). Parent-adolescent congruency in reports of adolescent sexual behavior and in communications about sexual behavior. Child Development, 69, 247-261.

Kirby, D. (2007). Emerging answers: research findings on programs to reduce teen pregnancy and sexually transmitted diseases. Washington: National Campaign to Prevent Teen Pregnancy.

Knight, G. P., Tein, J. Y., Shell, R., \& Roosa, M. (1992). The crossethnic equivalence of parenting and family interaction measures among Hispanic and Anglo-American families. Child Development, 63(6), 1392-1403.

Manlove, J., Logan, C., Moore, K. A., \& Ikramullah, E. (2008). Pathways from family religiosity to adolescent sexual activity and contraceptive use. Perspectives on Sexual and Reproductive Health, 40(2), 105-117.

Marin, B. V. (2003). HIV prevention in the Hispanic community: sex, culture, and empowerment. Journal of Transcultural Nursing, 14, $186-192$

Martin, J. A., Hung, H.-C., Mathhews, T. J., Hoyert, D. L., Strobino, D. M., Guyer, B., et al. (2008). Annual summary of vital statistics: 2006. Pediatrics, 121, 788-801.

Meneses, L. M., Orrell-Valente, J. K., Guendelman, S. R., Oman, D., \& Irwin, C. E., Jr. (2006). Racial/ethnic differences in motherdaughter communication about sex. Journal of Adolescent Health, 39(1), 128-131.

Miller, K. S., \& Whitaker, D. J. (2001). Predictors of mother adolescent discussions about condoms: implications for providers who serve youth. Pediatrics, 108(2): e28.

Nadeem, E., \& Romo, L. F. (2008). Low-income Latina mothers' expectations for their pregnant daughters' autonomy and interdependence. Journal of Research on Adolescence, 18(2), 215-238.

Nadeem, E., Romo, L. F., \& Sigman, M. (2006). Knowledge about condoms among low-income pregnant Latina adolescents in relation to explicit maternal discussion of contraceptives. Journal of Adolescent Health, 39(1), e9-e15.

National Campaign to Prevent Teen Pregnancy. (2001). With one voice: America's adults and teens sound off about teen pregnancy. A national survey. Washington: National Campaign to Prevent Teen Pregnancy.

Noldus Observer XT 7.0 (2007). Noldus Information Technology bv. The Netherlands.

Nonnemaker, J. M., McNeely, C. A., \& Blum, W. M. (2003). Public and private domains of religiosity and adolescent health risk 
behaviors: evidence from the national Study of Adolescent Health. Journal of Social Science \& Medicine, 57(11), 20492054.

O’Sullivan, L. F., Meyer-Bahlburg, H. F. L., \& Watkins, B. X. (2001). Mother-daughter communication about sex among urban African American and Latino families. Journal of Adolescent Research, 16(3), 269-292.

Raffaelli, M., \& Green, S. (2003). Parent-adolescent communication about sex: retrospective reports by Latino college students. Journal of Marriage and the Family, 65(2), 474-481.

Raffaelli, M., \& Ontai, L. L. (2001). "She's 16 years old and there's boys calling over to the house": an exploratory study of sexual socialization in Latino families. Culture, Health \& Sexuality, 3 (3), 295-310.

Raffaelli, M., Bogenschneider, K., \& Flood, M. (1998). Parent-teen communication about sexual topics. Journal of Family Issues, 19, 315-333.

Roche, K. M., Mekos, D., Alexander, C. S., Astone, N. M., BandeenRoche, K., \& Ensminger, M. E. (2005). Parenting influences on early sex initiation among adolescents: how neighborhood matters. Journal of Family Issues, 26(1), 32-54.

Romo, L. F., Lefkowitz, E. S., Sigman, M., \& Au, T. K. (2002). A longitudinal study of maternal messages about dating and sexuality and their influence on Latino adolescents. Journal of Adolescent Health, 31(1), 59-69.

Romo, L. F., Kouyoumdjian, C., Nadeem, E., \& Sigman, M. (2006). Promoting values of education in Latino mother-adolescent discussions about conflict and sexuality issues. In J. Denner \&
B. L. Guzman (Eds.), Latina girls: voices of adolescent strength in the US (pp. 59-76). New York: New York University Press.

Rosenbaum, J. E. (2009). Patient teenagers? A comparison of the sexual behavior of virginity pledgers and matched nonpledgers. Journal of Pediatrics, 123(1), 10-20.

Santelli, J., Ott, M. A., Lyon, M., Rogers, J., Summers, D., \& Schleifer, R. (2006). Abstinence and abstinence-only education: a review of US policies and programs. Journal of Adolescent Health, 38(1), 72-81.

Savin-Williams, R. C., \& Diamond, L. M. (2004). Sex. In R. M. Lerner \& L. Steinberg (Eds.), Handbook of adolescent psychology (2nd ed., pp. 189-231). Hoboken: Wiley.

Steinberg, L. (2005). Adolescence (7th ed.). New York: McGraw Hill.

Tolman, D. L., Striepe, M. I., \& Harmon, T. (2003). Gender matters: constructing a model of adolescent sexual health. Journal of Sex Research. Special Issue: Gender and Sexuality, 40(1), 4-12.

Vélez-Pastrana, M. C., González-Rodríguez, R. A., \& BorgesHernández, A. (2005). Family functioning and early onset of sexual intercourse in Latino adolescents. Adolescence, 40(160), 777-791.

Villarruel, A. M. (1998). Cultural influences on the sexual attitudes, beliefs, and norms of young Latina adolescents. Journal of the Society of Pediatric Nurses, 3(2), 69-79.

World Health Organization. WHO website. Available at: http://www. WHO.int/. Accessed 2006.

Zavella, P. (2003). Talkin' sex: Chicanas and Mexicanas theorize about silences and sexual pleasures. In G. Arredondo, A. Hurtado, N. Klahn, O. Nájera Ramírez, \& P. Zavella (Eds.), Chicana Feminisms: A Critical Reader. Durham: Duke University Press. 